\title{
Yüksek Gerilim Kablolarında k-NN ile Arıza Konumu Belirleme ve Veri Boyutunun Sınıflandırmaya Etkileri
}

\author{
Fatih Serttaş ${ }^{1}$, Tuba Nur Serttaş ${ }^{2}$, Fatih Onur Hocaoğlu ${ }^{1}$ \\ ${ }^{1}$ Afyon Kocatepe University, Engineering Faculty, Electrical Engineering, Afyonkarahisar Turkey \\ ${ }^{2}$ Afyon Kocatepe University, Technology Faculty, Electrical - Electronic Engineering, Afyonkarahisar Turkey \\ e-posta: serttasf@gmail.com ,ORCID ID:http://orcid.org/0000-0003-3109-716X
}

Geliş Tarihi: 10.09.2021 ; Kabul Tarihi:26.11.2021

Öz

Yüksek gerilim elektrik tesislerindeki kablolarda meydana gelen arızaların büyük bir kısmı, kısmi boşalma kaynaklı yalıtım sorunlarından oluşmaktadır. Bu tür arızalar, genellikle kablolar üzerindeki montaj kusurlarından, nadir olarak da üretim hatalarından kaynaklanmaktadır. Bu çalışmada, yüksek ve orta gerilim sistemlerinde kullanılan çapraz bağlı polietilen yer altı kabloları (XLPE) üzerindeki kusurların

Anahtar kelimeler

Kısmi boşalma; yüksek gerilim; K-NN; arıza tanılama; konumlarının belirlenmesi amacıyla, bir dizi deneysel çalışmalar gerçekleştirilmiştir. Laboratuvar ortamında, farklı mesafelerde kusurları bulunan aynı türde XLPE kablo numunelerine aynı orta gerilim seviyesinde gerilim belirli periyotlarda uygulanmış ve elde edilen kısmi boşalma sinyalleri zaman serisi olarak dijital ortama kaydedilmiştir. Kaydedilen veriler k En Yakın Komşuluklar (k-NN) yöntemiyle sınıflandırılmış ve sınıflandırma doğrulukları, veri azaltma yöntemi ile analiz edilmiştir. Veri azaltmadaki amaç, pek çok farklı ölçüm frekansında modelin doğru sınıflandırmalar yapabildiğini gözlemlemek ve daha düşük frekans bandında çalışan cihazlarla yapılacak ölçümlerin doğruluğunu test etmektir. Sonuçlar k-NN yönteminin, kısmi boşalma sinyallerinin incelenmesinde yüksek oranda başarılı sonuçlar verdiğini göstermekte ve verilerin büyük oranda azaltılmasının, istatistiksel öznitelikler kullanıldığında, sınıflandırma doğruluğunu etkilemediğini göstermektedir.

\section{Fault Location Detection with k-NN in High Voltage Cables and Effects of Data Size on Classification}

\begin{abstract}
In high voltage electrical installations, most of the faults in cables are caused by insulation problems caused by the partial discharge. Such failures are usually caused by assembly defects on the cables and rarely by manufacturing defects. In this study, a series of experimental studies were carried out to determine the locations of defects on cross-linked polyethylene underground cables (XLPE) used in high and medium voltage systems. The same medium voltage level was applied to the same type of XLPE cable samples with defects at different distances at specific periods in the laboratory environment. The partial discharge signals obtained were recorded in the digital environment as time series. Recorded data were classified by the $k$ Nearest Neighborhood (k-NN) method, and classification accuracies were analyzed by the data reduction method. The purpose of data reduction is to observe that the model can make accurate classifications at many different measurement frequencies and test the accuracy of the measurements with devices operating in the lower frequency band. The results show that the k-NN method gives highly successful results in analyzing partial discharge signals and shows that the considerable reduction of data does not affect the classification accuracy when statistical features are utilized.
\end{abstract}

Keywords

Partial discharge; high voltage; K-NN; failure diagnostic; 


\section{Giriş}

Yüksek ve orta gerilim elektrik şebekelerinde, XLPE güç kabloları, en yaygın kullanılan kablo türlerinden birisidir. Elektromanyetik güvenilirlik, fiziksel dayanım gibi pek çok faktör, bu kabloları tercih sebebi yapmaktadır. Günümüzde kablo üretim tesisleri, oldukça yüksek verimlilikte kaliteli kablolar üretmekte ve üretim kaynaklı kablo arızalarını minimize etmektedir. Ancak üretim esnasında kablo yalıtkanı üzerinde oluşabilecek küçük bir boşluk (çizik, kesik gibi küçük kusurlar) oluşması veya kabloların tesiste montajı sırasında yaşanabilecek işçilik hataları, kabloların kısa vadede ömrünü tüketebilen, daha da önemlisi can ve mal kaybına neden olabilecek iş kazalarına sebebiyet veren önemli konulardır. Yalıtımların, malzemenin gerilim seviyelerine uygun ve hasar görmemiş, topraklamaların doğru yapılandırılmış olması gerekmektedir. Yüksek gerilim mühendisliğinde yalıtım koordinasyonu, üzerinde durulması gereken önemli bir husustur. Kısmi boşalma (KB) ölçüm ve analizleri, yüksek gerilim teçhizatının yalıım kalitesini belirlemede önemli bir ölçüt olarak kabul edilmektedir. Bu ölçümlerin gerçekleştirilmesinde, IEC60270 gibi pek çok uluslararası standart belirleyici olmaktadır.

Yüksek gerilim XLPE kablolarında boşluklarda oluşan kısmi boşalmaların net bir şekilde anlaşılabilmesi için iyi bir gözlem ve ölçüm takibi gereklidir (Joseph vd. 2019). Çeşitli nümerik yöntemlerle, XLPE kabloların bilgisayar ortamında benzetimi gerçekleştirilmekte ve kısmi boşalma olayları analiz edilmektedir. Analizler çevrim içi ve çevrim dışı yöntemler kullanılarak gerçekleştirilebilmektedir (Adhikari ve Kalla 2020). 1990 Iı yıllarda önerilen yansıma zamanı farklılıkları yönteminin üzerine yıllar içerisinde bilim insanları tarafından çeşitli yöntemler geliştirilmiştir (Mashikia vd. 1990). Cavallini vd. (2007) tarafından geliştirilen genlik-frekans haritalamaya dayalı yöntem, Mardiana ve Su (2010) tarafından önerilen faz farkına dayalı yöntem ve Sheng vd. (2015) tarafından sunulan darbe yükselme zamanı ve aktarım fonksiyonu (RTTF) yöntemi literatürde bulunabilecek yöntemlere örnek olarak ele alınabilir. Bunların yanı sıra ANSYS ve EMTP gibi yazılımlar yardımıyla da elektromanyetik analizler gerçekleştirilebilmektedir. Analizler başarılı sonuçlar verse de, deneysel çalışmalarla desteklenmesi ve doğruluklarının tartışılması gerekmektedir. Khan vd. (2021), gelişmiş bir sonlu eleman tabanlı hesaplama algoritması kullanılarak farklı boşluklar modellemiş ve analiz etmiştir. Önerilen yaklaşım, şekil ve boyutlarından bağımsız olarak boşluklarda ve boşluklarda KB'yi ölçmek için kullanılmaktadır. Kısmi boşalma davranışı, benzetimi yapılmış KB sinyalinden elde edilen KB istatistiksel özellikleri aracılığıyla incelenmiş ve analiz edilmiştir. Önerilen modelleme yaklaşımının doğruluğunu doğrulamak için benzetim yapılmış ve deneysel sonuçlar arasında karşılaştırmalı bir çalışma da yapılmıştır.

Pattanadech ve Nimsanong (2014), kısmi boşalma (KB) sınıflandırması için dört istatistiksel sınıflandırma modelinin karşılaştırmasını önermişlerdir. Bu dört yöntem şu şekilde sıralanabilir: k-en yakın komşuluklar (k-NN) modeli, olasılıksal sinir ağı (PNN) modeli ve temel bileşen analizini (PCA) kullanan PCA-KNN ile PCA-PNN modelidir.

Yüksek frekanslı akım trafosu ( HFCT) ve UHF yöntemlerinin kablo arızalrı tespitinde etkili olduğuda çeşitli çalışmalarla ortaya konulmuştur (Jahangir vd. 2017, Dukanac 2017). UHF sensörlerinin yer altı kablolarındaki arızaların tespiti için kullanıldığı çalışma örneklerinde ise, deney veya çevrimiçi koşulda yapılan tüm testlerden sonra, kablodaki doğru PD konumunu elde etmek için kırpılmış ortalama veri filtresi tekniği kullanılarak verilerin analiz edilebileceği gösterilmiştir (Muslim vd. 2013, Yii vd. 2015).

Dönüştürücü transformatör için kNN tabanlı bir tür arıza teşhis yöntemi önerilmiştir. Dört tip yapay yağlı kâğıt yalıım hatası tasarlanmış ve KB sinyallerini toplamak için UHF (Ultra Yüksek Frekans) anteni kullanılmıştır (Liu vd. 2013). Toplanan KB UHF sinyallerinin enerji katsayılarını hesaplamak için çok ölçekli dalgacık paket dönüşümü gerçekleştirilmiş ve karakteristik parametrelerini tanımak için kNN algoritması 
uygulanmıştır. BPNN (Geri Yayılımlı Sinir Ağı) tarafından tanınan KB modu, önerilen algoritma ile karşılaştırılmış; bu, ikincisinin dönüştürücü transformatörün arıza teşhisi için daha uygun olduğunu gösterilmiştir. Deneysel olarak elde edilen veriler ile yapılan çalışmalarda en büyük dezavantaj yüksek gürültü oranıdır.

Lan vd. (2019) önerdikleri faz farkı yöntemini uygularken kullandıkları veriyi düşük gürültülü ortamda elde etmişlerdir.

Muhr ve Woschitz (2000), $50 \mathrm{~Hz}$ ve $0, \mathrm{lHz}$ test geriliminde kablo arızaları için kısmi deşarj tespiti ve lokalizasyonu için bir karşılaştırma sunmaktadır. Ölçüm sistemi, kablo boyunca PD darbelerinin karakteristik yayılımı ve zayıflaması ilkesine göre çalışır. Bu çalışmada da aynı prensipten yola çıkılarak elde edilmiştir.

Literatürdeki çalışmalarla eşgüdümlü olarak ve yüksek gerilim mühendisliğine kazanım sağlayacak şekilde yapılan bu çalışmada, deneysel olarak kablolarda kusurlar meydana getirilmiş (2. Bölüm) ve bu kusurların konumlarının belirlenmesinde $k$ NN yöntemiyle KB verileri sınıflandırılmıştır (3. Bölüm). Verilerin istatistiksel özniteliklerinin yüksek doğrulukla sınıflandırıldığı bu teknikte, kullanılan KB verilerinin boyutu her sefer yarıya indirilmiş ve yeniden sınıflandırma gerçekleştirilmiştir. Yapılan testlerin tüm aşamalarındaki sonuçlar bulgular kısmında mevcuttur. Elde edilen bulgular, analiz sonuçları ve gelecekte yapılabilecek çalışma önerileri, tartışma ve sonuç kısmında sunulmuştur.

\section{Materyal ve Metot}

Numune olarak hazırlanan, Şekil 1'de çizimi yapılarak gösterilen $50 \mathrm{~mm} 2^{\prime}$ lik XLPE güç kablolarının, yaklaşık 10 kV enerji altında, kuplaj kondansatörlü sistem ve portatif bir KB ölçüm cihazı aracılığıyla laboratuvar ortamında kısmi boşalma ölçümleri gerçekleştirilmiştir. Eşit uzunlukta ve kesitteki numune XLPE kabloların iki farklı konumunda kusur meydana getirilmiştir. $\mathrm{Bu}$ kusurlar montajda oluşabilecek kusurların benzetimi şeklinde gerçekleştirilmiştir. Sırayla çeşitli ölçümler gerçekleştirilerek veri toplanmıştır. Ölçümlerin gerçekleştirildiği test düzeneği Şekil 2 'de verilmiştir. Test geriliminin belirlenmesinde,
KB sinyallerinin belirgin gözlenmeye başladığı gerilim seviyesi tercih edilmiştir. Gerilim, 1 kV seviyelerinden yavaş yavaş artırılarak KB darbeleri gözlenmiş, 5 kV seviyelerinde KB'ler rassal olarak gözlenmeye başlamış ve $10 \mathrm{kV}$ gerilimin sinyal sınıflandırma için yeterli olacağı görülmüştür. Kısmi boşalma sinyallerinin grafiksel gösterimi Şekil 3'te sunulmuştur. Grafik, ölçümlerin yalnızca küçük bir parçasını oluşturmaktadır. Grafikteki mavi olan sinyal, kısmi boşalma ölçümünü ifade etmektedir. Görülen küçük darbe gerilimleri, KB darbeleridir. Yaklaşık $300 \mathrm{mV}$ tepe gerilimindedir. Uygulanan besleme gerilimiyse yaklaşık 10.000 kat küçültülmüş olarak görülmektedir. Kablo dayanımı gözetilen KB testlerinde, kablo gerilim kapasitesinin üzerinde yüksek gerilimler uygulanması gerekmektedir. Ancak bu çalışmada, KB sinyallerinin sınıflandırılmaları ve veri boyutunun bu sınıflandırmalara etkisi üzerinde durulduğundan, gerilim seviyesi kritik yüksekliklerde tercih edilmemiş, kısmi boşalmaların görülmesi yeterli bulunmuştur. Bu da daha düşük gerilim seviyelerinde de testi gerçekleştirebilme olanağı sağlamıştır.

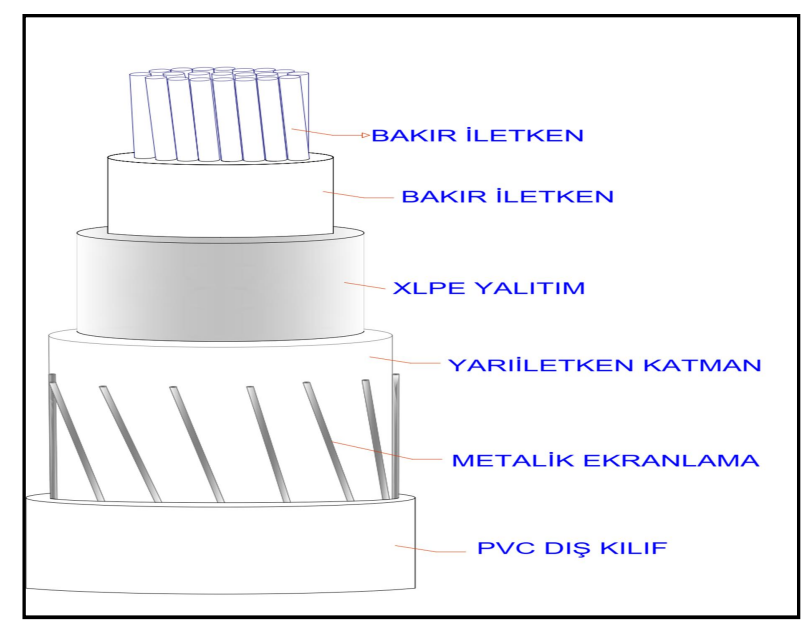

Şekil 1. Kullanılan XLPE kablo yapısı

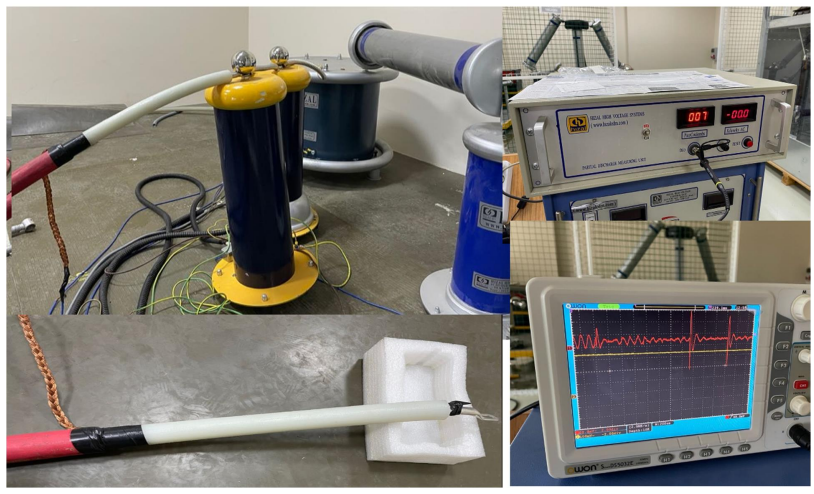

Şekil 1. Kullanılan test düzeneği 


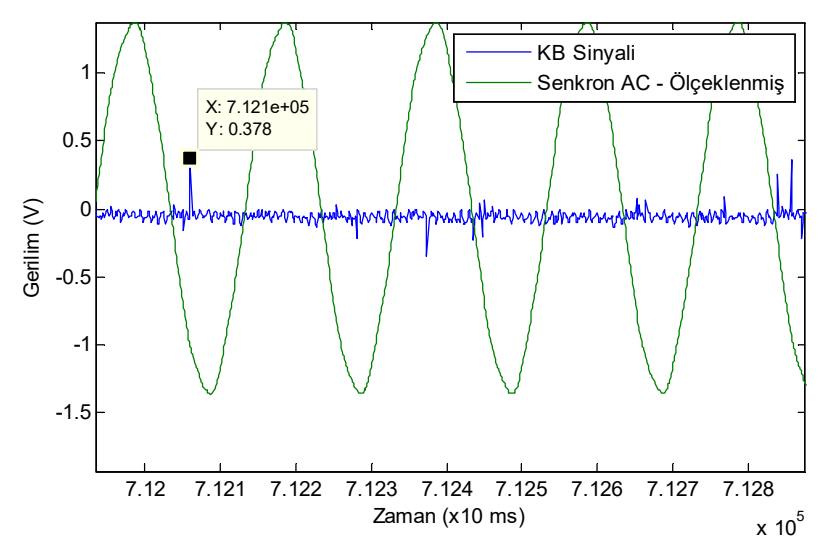

Şekil 3. Laboratuvarda ölçülen KB sinyali (mavi) ve uygulanan ölçeklendirilmiş AC gerilimi (yeşil).

\subsection{Kuplaj kondansatörlü sistem}

Zaman serisi olarak verilerin kaydedilmesinde, IEC60270 standardına uygun şekilde, geleneksel yöntem olarak kabul edilen kuplaj kondansatörlü sistem tercih edilmiş, portatif cihaz ile ölçümlerin doğruluğu test edilmiş ve KB sinyal bilgileri çeşitlendirilmiştir. Standart ölçüm devresi düzeneği Şekil 4'te sunulmuştur.

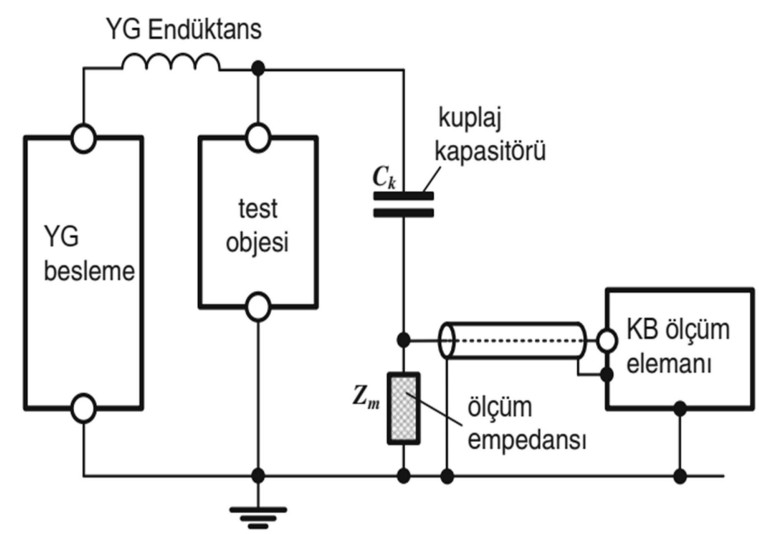

Şekil 4. IEC60270 standardına göre KB ölçüm düzeneği.

\subsection{Kısmi boşalma sinyallerinin sınıflandırılması}

Laboratuvarda ölçülen KB sinyalleri, sayısal veriler olarak depolandıktan sonra bu verilerden istatistiksel parametreler ile öznitelik çıkarımı yapılmıştır. Verilerin ham halinde boyutları oldukça büyük olmakta ve sınıflandırma doğruluğu başarılı olmamaktadır. İstatistiksel öznitelik çıkarımı ile yeni, çok küçük boyutlu fakat anlamlı veriler elde edilmektedir. Kısmi boşalma sinyallerinin işlenmesinde yaygın olarak tercih edilen ortalama, varyans, standart sapma, kurtosis ve skewness parametreleri, bu çalışmada da öznitelik çıkarımında kullanıımıştır.

\subsection{K-NN ile sınıflandırma}

Sınıflandırma yöntemlerinden olan $k$ en yakın komşuluk (k-NN) yöntemi, mevcut tüm durumların saklanacağı ve mesafe ölçümü gibi bir benzerlik kriterine göre yeni bir durumun sınıflandırılacağı parametrik olmayan bir yöntemdir. Hedef ve en yakın komşular arasındaki mesafeyi değerlendirmek için, mesafe fonksiyonu seçilmelidir. k-NN sınıflandırması için Öklid mesafesi, Manhattan mesafesi, Minkowski mesafesi veya Hamming mesafesi uygulanabilir. $\mathrm{Bu}$ çalışmada, Öklid uzaklığı fonksiyonu Eşitlik 1 olarak kullanılmıştır.

$$
\text { Öklid Mesafesi }=\sqrt{\sum_{i=1}^{k}\left(x_{i}-y_{i}\right)^{2}}
$$

Bu denklemde $x$ giriş vektörü, y eğitim vektörü ve $k$ sınıflandırmada kullanılan en yakın komşu sayısıdır. Komşu sayı ve uzaklıklarının görülebileceği, yöntemin temsili olarak gösterildiği grafik Şekil 5'te sunulmuştur.

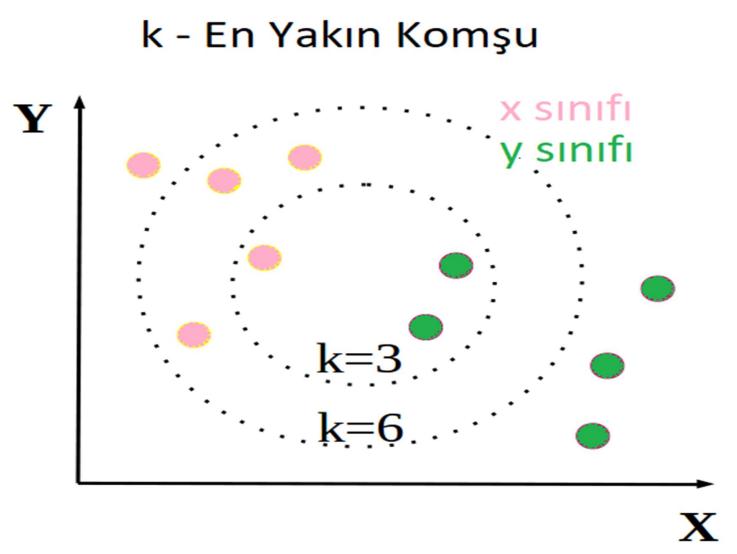

Şekil 5. k-NN temsili grafiği.

\subsection{Veri azaltma tekniği}

Ölçüm verileri her bir aşamada yarıya indirilmiştir ve her aşamada azaltılan bu verilerin istatistiksel öznitelikleri çıkarılmıştır. Bu öznitelikleri varyans, standart sapma, kurtosis, skewness ve ortalama değer meydana getirmektedir. Adı geçen istatistiksel parametrelerden oluşan matrisler, kNN yönteminde öznitelik olarak kullanılmıştır. Sınıflandırmalar, verilerin azaltılmasıyla oluşturulan güncel özniteliklere göre tekrarlanmıştır. 
Başlangıçta ölçülen veri sayısı ise, ölçümün alındığı veri kayıt cihazının frekansına bağlı olarak değişmektedir. Veri azaltmanın sonucu olarak, başarılı sınıflandırmanın yapılabildiği en az veri, cihazların temininde frekans bandı özelliği açısından ekonomik boyutlandırma için fikir vermektedir.

\section{Bulgular}

$\mathrm{Bu}$ çalışmada, XLPE kablo üzerinde iki farklı konumdaki kusurlara ait olan veriler kullanılarak konum sınıflandırması (arıza konumlama-tanılama) yapılmıştır. Kablonun ilk yarısında oluşturulmuş olan kusur ile 1 numaralı sınıfa ait veriler elde edilirken ikinci yarısında oluşturulan kusur sonucunda 2 numaralı sınıfa ait veriler elde edilmiştir. İstatistiksel parametreler kullanılarak hazırlanan öznitelik matrislerinden birine ait örnek Çizelge 1'de sunulmuştur.

Çizelge 1. Öznitelik matrisi.

\begin{tabular}{|c|c|c|c|c|c|c|c|c|c|c|c|c|}
\hline \multirow{2}{*}{ Öznitelik } & \multicolumn{6}{|c|}{ Sinıf 1} & \multicolumn{6}{|c|}{ Sinıf 2} \\
\hline & Deney 1 & Deney 2 & Deney 3 & Deney 4 & $\begin{array}{l}\text { Deney } 5 \\
\end{array}$ & Deney 6 & Deney 1 & Deney 2 & Deney 3 & Deney 4 & Deney 5 & Deney 6 \\
\hline Ortalama & 1,04 & 1,29 & 1,38 & 1,33 & 0,20 & 1,82 & 55,55 & 58,52 & 64,05 & 61,63 & 62,26 & 50,35 \\
\hline $\begin{array}{l}\text { Standart } \\
\text { sapma }\end{array}$ & 28,38 & 32,31 & 34,03 & 29,78 & 41,54 & 35,83 & 3085,8 & 3424,3 & 4102,06 & 3797,80 & 3876,88 & 2535,04 \\
\hline Varyans & 805,2 & 1044,1 & 1158,1 & 886,8 & 1725,3 & 1284,0 & 17,01 & 11,22 & 13,94 & 14,34 & 11,76 & 9,75 \\
\hline Kurtosis & 45,39 & 57,49 & 56,41 & 41,01 & 69,46 & 56,34 & 1,35 & 1,40 & 1,45 & 1,23 & 1,20 & 1,09 \\
\hline Skewness & 3,34 & 3,89 & 4,08 & 4,09 & 4,31 & 4,17 & 3,34 & 3,89 & 4,08 & 4,09 & 4,31 & 4,17 \\
\hline
\end{tabular}

Çizelge 1 ikiye ayrılmıştır. İlk bölümde birinci arıza konumunda yapılan deneylerden elde edilen istatistiksel parametreleri, ikinci bölüm ikinci arıza konumunda yapılan deneylerden elde edilen istatistiksel parametreleri ifade etmektedir. K-NN yöntemi ile yapılan sınıflandırma işlemlerine ait sonuçlar ise Çizelge 2'de verilmiştir. Yapılan analizler kullanılan veri miktarının sınıflandırma doğruluğu üzerindeki etkisini ortaya koymaktadır. Veri sayısının belirli bir sayının altına inmesi sınıflandırma doğruluğunun da düşmesine sebep olmuştur. Aynı zamanda doğruluk yüzdesini arttırmak için kullanılan veri sayısının sonsuza kadar arttırılmasının da anlamlı bir yaklaşım olmadığı görülmektedir. Bu noktada önemli olan kısmi boşalma karakteristiğini ortaya koyan grafiğin elde edilebileceği veri sayısıdır. Bu nedenle büyük veri boyutları ile uğraşmak yerine kısmi boşalma eğrisine ait karakteristik özellikler elde edilerek bu karakteristiği ortaya koyacak en az sayıdaki veri ile çalışmak hedeflenmelidir. Yapılan bu çalışmada verilerin \%100'ünün kullanılması ile \%6,25'nin kullanımı ile yapılan sınıflandırmada eşit doğruluk görülmektedir. Bu durum deneyler sonucunda elde ettiğimiz verilerin \%6,25' inin arıza konumu tespiti için yeterliği niteliği karşıladığını göstermektedir.

Çizelge 2. Veri azaltmanın sınıflandırma başarı yüzdelerine etkisi.

\begin{tabular}{lllllllllllllll}
\hline $\begin{array}{c}\text { Konum } \\
\text { Veri Boyutu }\end{array}$ & $\mathbf{1}$ & $\mathbf{1}$ & $\mathbf{1}$ & $\mathbf{1}$ & $\mathbf{1}$ & $\mathbf{1}$ & $\mathbf{2}$ & $\mathbf{2}$ & $\mathbf{2}$ & $\mathbf{2}$ & $\mathbf{2}$ & $\mathbf{2}$ & $\begin{array}{l}\text { Başarı } \\
\text { Yüzdesi(\%) }\end{array}$ \\
\hline 3040 veri & 1 & 1 & 1 & 1 & 1 & 1 & & 2 & 2 & 2 & 2 & 2 & 2 & 100 \\
1520 veri & 1 & 1 & 1 & 1 & 1 & 1 & & 2 & 2 & 2 & 2 & 2 & 2 & 100 \\
760 veri & 1 & 1 & 1 & 1 & 1 & 1 & & 2 & 2 & 2 & 2 & 2 & 2 & 100 \\
380 veri & 1 & 1 & 1 & 1 & 1 & 1 & & 2 & 2 & 2 & 2 & 2 & 2 & 100 \\
190 veri & 1 & 1 & 1 & 1 & 1 & 1 & & 2 & 2 & 2 & 2 & 2 & 2 & 100 \\
95 veri & 1 & 1 & 1 & 1 & 2 & 1 & & 2 & 2 & 2 & 2 & 2 & 1 & 83 \\
48 veri & 1 & 1 & 1 & 1 & 2 & 2 & 2 & 1 & 2 & 2 & 2 & 1 & 67 \\
\hline
\end{tabular}

\section{Tartışma ve Sonuç}

Sınıflandırma yöntemleriyle, kısmi boşalma ölçümlerini kullanarak yalıtım arızası sınıflandırma, son zamanlarda yaygın olarak kullanılan tekniklerdendir. Kısmi boşalma ölçümlerinde ölçüm süresi, ölçüm frekansı, bant genişliği gibi etkenler veri büyüklüğünü etkileyen önemli parametrelerdir. Ölçüm cihazlarının frekans bandı ve örnekleme sayısı arttıkça fiyatları da oldukça yükselmektedir. Veri boyutlarının büyümesiyle, veri işleme de zorlaşmakta, harcanan zaman ve efor artış göstermekte, yüksek hızlı bilgisayarlara ihtiyaç duyulmaktadır. Bu çalışmada k-NN ile kısmi boşalma verilerinin sınıflandırılması 
gerçekleştirilirken, kullanılan veri sayısı da aşamalı olarak seyreltilerek çıkıştaki doğruluk değerleri güncellenmiştir. Laboratuvar ortamında kaydedilen veriler için k-NN yöntemiyle sınıflandırma başarılı sonuçlar vermektedir. Veriler azaltıldıkça, çok daha az boyutlu ölçüm verileriyle de başarılı sınıflandırmalar yapılabildiği görülmüştür.

Çalışmada kısmi boşalma verileri, ham veri halinde sınıflandırıcıda kullanılmamış, istatistiksel özniteliklere dönüştürülmüştür. Bu çalışma için veri boyutu, başlangıçtaki halinin \%1,5 değerine kadar azaltılmış, \%6,25 değerlerinde ise sınıflandırma doğruluğu halen \%100 olarak kalmıştır. Bu örnekleme sıklığında bir cihaz kullanılan cihaza göre oldukça düşük maliyetli bir cihaz olacaktır.

Makale çalışması birçok açıdan geliştirmelere açıktır. Gelecek çalışmalarda, kablo üzerindeki arıza konum yeri sayısı artırılabilir ve sınıflandırma doğruluğu test edilebilir. Veri boyutları farklı frekanslarda ölçülüp, azaltarak denenebilir. İstatistiksel öznitelikler yerine, farklı öznitelikler çıkarılıp sınıflandırmada kullanılabilir. En yakın komşuluklar yöntemi yerine destek vektör makineleri gibi farklı yöntemlerdeki sınıflandırma başarıları test edilebilir durumdadır.

\section{Kaynaklar}

Adhikari, N., and Kalla, U. K. (2020). Analysis of Partial Discharge Measurements in High Voltage XLPE Cable. In 2020 IEEE 9th Power India International Conference (PIICON) (pp. 1-5). IEEE.

Cavallini, A., Montanar, G.C. and Puletti, F., 2007. A novel method to locate $P D$ in polymeric cable systems based on amplitude-frequency (AF) map. IEEE Transactions on Dielectrics and Electrical Insulation, 14, 3, 726-734.

Dukanac, D. (2018). Application of UHF method for partial discharge source location in power transformers. IEEE Transactions on Dielectrics and Electrical Insulation, 25(6), 2266-2278.

Jahangir, H., Akbari, A., Werle, P., and Szczechowski, J. (2017). UHF PD measurements on power transformers-advantages and limitations. IEEE Transactions on Dielectrics and Electrical Insulation, 24(6), 3933-3940.

Joseph, J., Mohan, S. and Krishnan, S.T., 2019. Numerical modelling, simulation and experimental validation of partial discharge in cross-linked polyethylene cables.
IET Science, Measurement and Technology, 13, 2, 309-317.

Khan, Q., Refaat, S.S., Abu-Rub, H., Toliyat, H.A., Olesz, M. and Darwish, A., 2021. Characterization of Defects Inside the Cable Dielectric With Partial Discharge Modeling. IEEE Transactions on Instrumentation and Measurement, 70, 1-11.

Lan, S., Hu, Y.Q. and Kuo, C.C., 2019. Partial discharge location of power cables based on an improved phase difference method. IEEE Transactions on Dielectrics and Electrical Insulation, 26, 5, 1612 1619.

Liu, F., Zhang, Y., Yao, X., Peng, Q., Nie, H., Li, J. and Zhou, Q., 2013. Recognition of PD mode based on KNN algorithm for converter transformer. Dianli Zidonghua Shebei/Electric Power Automation Equipment, 33, 5, 89-93.

Mardiana, R. and Su, C.Q., 2010. Partial discharge location in power cables using a phase difference method. IEEE Transactions on Dielectrics and Electrical Insulation, 17, 6, 1738-1746.

Mashikian, M.S., Bansal, R. and Northrop, R.B., 1990. Location and characterization of partial discharge sites in shielded power cables. IEEE Transaction Power Delivery, 5, 2, 833-839.

Muhr, M. and Woschitz, R., 2000. Partial discharge diagnostic. Proceedings of the 6th International Conference on Properties and Applications of Dielectric Materials, 1, 223-226.

Muslim, J., Susilo, A., Nishigouchi, K., Kozako, M., Hikita, M., Arief, Y. Z., and Khayam, U. (2013, September). Enhanced bowtie UHF antenna for detecting partial discharge in gas insulated substation. In 2013 48th International Universities' Power Engineering Conference (UPEC) (pp. 1-5). IEEE.

Pattanadech, N. and Nimsanong, P., 2014. Effect of noise signals on partial discharge classification models. TENCON 2014 - 2014 IEEE Region 10 Conference, 1-5.

Sheng, B., Zhou, C., Hepburn, D.M., Dong, X., Peers, G., Zhou, W. and Tang, Z., 2015. A novel on-line cable pd localisation method based on cable transfer function and detected pd pulse rise-time. IEEE Transactions on Dielectrics and Electrical Insulation, 22, 4, 20872096.

Yii, C. C., Rohani, M. N. K. H., Isa, M., Hassan, S. I. S., Ismail, B., and Hussin, N. (2015, December). Multiend partial discharge location algorithm based on trimmed mean data filtering technique for $\mathrm{MV}$ underground cable. In 2015 IEEE Student Conference on Research and Development (SCOReD) (pp. 345350). IEEE. 